\title{
Clinical significance of hepatocyte growth factor/c-Met expression in the assessment of gastric cancer progression
}

\author{
EIICHIRO NOGUCHI ${ }^{1}$, NOBORU SAITO ${ }^{1}$, MAKIO KOBAYASHI $^{2}$ and SHINGO KAMEOKA ${ }^{1}$ \\ Departments of ${ }^{1}$ Surgery II and ${ }^{2}$ Pathology I, Tokyo Women's Medical University, Tokyo 162-8666, Japan
}

Received April 1, 2014; Accepted December 12, 2014

DOI: $10.3892 / \mathrm{mmr} .2015 .3205$

\begin{abstract}
Among the mechanisms that control cancer progression, cell mobility is a significant factor required for cellular liberation from the primary focus and infiltration. Hepatocyte growth factor (HGF) has been shown to facilitate cell mobility. In the present study, the clinical significance of the HGF/c-Met pathway in the assessment of gastric cancer progression was evaluated. From a cohort of patients with gastric cancer who underwent surgical resection between April 1999 and March 2003, 110 subjects were randomly selected. Preoperative serum HGF levels were measured and various pathological factors were analyzed. Furthermore, 50 subjects were randomly selected from within this group and immunohistochemical staining of tissue preparations for HGF and its receptor c-Met were performed. In the infiltrative growth pattern [(INF) $\alpha, \beta$ vs. INF $\gamma]$, advanced progression was associated with elevated preoperative serum HGF levels $(\mathrm{P}<0.001)$. No correlation was identified between serum HGF levels and immunostaining for HGF or c-Met in the tissue preparations. Immunostaining revealed a significant correlation between c-Met expression and lymphatic vessel invasion (ly0.1 vs. 2.3; $\mathrm{P}=0.0416$ ), lymph node metastasis (n0.1 vs. $2 ; \mathrm{P}=0.0184$ ) and maximum tumor diameter ( $\leq 50 \mathrm{~mm}$ vs. $>50 \mathrm{~mm} ; \mathrm{P}=0.0469$ ). Furthermore, c-Met-positivity was associated with a significant difference in overall survival ( $\mathrm{P}=0.0342)$, despite stage I and II cases accounting for $82 \%$ of the total cohort (41 of 50 cases). These results suggested that the expression of the HGF/c-Met pathway in gastric cancer may be a potential predictive factor for disease progression.
\end{abstract}

\section{Introduction}

Among the mechanisms that mediate cancer progression, cell mobility is a significant factor necessary for liberation

Correspondence to: Dr Noboru Saito, Department of Surgery II, Tokyo Women's Medical University, 8-1 Kawada-cho, Tokyo 162-8666, Japan

E-mail: nobosaito@surg2.twmu.ac.jp

Key words: hepatocyte growth factor, c-Met, gastric cancer prognosis, risk factor from the primary focus and infiltration. Various cell growth factors (1-5), including epidermal growth factor, transforming growth factor $\beta(6,7)$ and hepatocyte growth factor (HGF) (8), are known to facilitate cell mobility.

HGF, which was first isolated and cloned by Nakamura et al (9-12), performs various biological activities in cells, including stimulation of cell growth, promotion of migration, induction of morphogenesis and anti-apoptotic activities, via the c-Met receptor, which is a transmembrane protein containing a tyrosine kinase domain (13-15). The involvement of HGF in the infiltration/metastasis of cancer cells was first suggested in 1991, in a study in which the scatter factor, isolated as a fibroblast-derived bioactive factor with cell stimulatory activities in various cultured epithelial and cancer cells, was found to share an identical structure to that of the HGF molecule $(16,17)$. The functions of HGF were further elucidated by in vitro and in vivo analyses using various types of cancer cell $(18,19)$. Activation of the HGF/c-Met pathway leads to simultaneous activation of multiple signal transduction pathways that promote the infiltration of cancer cells and is considered to underlie the potent infiltrative/stimulatory effect of HGF (20-25). Genetic mutations of the c-Met receptor have been reported in various cancer types, including papillary renal (20-21), hepatic (22), gastric (23) and pulmonary cancer $(24,25)$, and the overexpression of c-Met has also been reported in numerous cancer tissues (26). Therefore, if the c-Met receptor is present in cancer cells, HGF antagonists should be able to inhibit multiple signal transduction pathways that lead to cancer cell infiltration, thereby exerting potential anti-cancer effects (27).

In a previous study by our group, an association between elevated pre-operative serum HGF levels and advanced disease stages in colon cancer was identified, mainly regarding the depth of tumor invasion into the wall and liver metastasis, which suggested the expression of the HGF/c-Met pathway as a potential predictive factor of colon cancer progression (8). In the present study, serological and immunohistological analyses were conducted in order to evaluate the clinical significance of the expression of the HGF/c-Met pathway in assessing the stage of gastric cancer progression.

\section{Materials and methods}

Patients. Subjects $(\mathrm{n}=110)$ were randomly selected from a cohort of patients with gastric cancer who underwent surgical 
resection at the Department of Surgery II, Tokyo Women's Medical University (Tokyo, Japan) between April 1999 and March 2003. Verbal consent was obtained from all patients upon hospitalization and written consent was obtained on the inpatient treatment plan. The study was conducted in 2005 in accordance with the ethical guidelines established by the updated Declaration of Helsinki and Tokyo Women's Medical University. Preoperative serum HGF levels in these subjects were measured and various pathological factors were analyzed. For 50 of these patients, immunohistochemical staining of tissue preparations for HGF and c-Met was additionally performed in order to analyze various factors identified in serological analysis.

The subjects comprised 83 males and 27 females aged 29-84 years [mean \pm standard deviation (SD), 62.8 \pm 9.9 years]. The tissue samples were histologically classified as follows: Four as papillary adenocarcinoma, 51 as tubular adenocarcinoma (25 as well-differentiated and 26 as moderately differentiated), 45 as poorly differentiated adenocarcinoma, six as signet-ring cell carcinoma and three as mucinous adenocarcinoma. The histological classification of invasion depth was as follows: Mucosa (m) in 28 patients, submucosa (sm) in 31 patients, muscularis propria (mp) in 11 patients, subserosa (ss) in 18 patients and serosa (se) in 22 patients. The stage classification was IA in 55 patients, IB in 18 patients, II in 16 patients, IIIA in nine patients, IIIB in six patients and IV in six patients (Table I). Data obtained from 200 healthy individuals were used as the control. Healthy individuals comprised patients undergoing surgery for benign diseases, including inguinal hernia or hemorrhoid, and healthy volunteers. Classification of infiltrative growth pattern (INF) was performed according to the General Rules for the Gastric Cancer Society, by the Japanese Research Society for Gastric Cancer, which is based on the Union for International Cancer Control criteria (28).

The 50 subjects that were subjected to immunostaining comprised 38 males and 12 females, with a mean age of $61.8 \pm 10.6$ years (range, 29-81 years). The tissue samples were histologically classified as follows: One as papillary adenocarcinoma, 23 as tubular adenocarcinoma (12 well-differentiated and 11 moderately differentiated), 20 as poorly differentiated adenocarcinoma, five as signet-ring cell carcinoma and one as mucinous adenocarcinoma. The histological classification of invasion depth was as follows: $m$ in 13 patients, sm in 15 patients, $\mathrm{mp}$ in five patients, ss in eight patients and se in nine patients. The stage classification was IA in 25 patients, IB in seven patients, II in nine patients, IIIA in four patients, IIIB in two patients and IV in three patients (Table II).

Serological analysis. Serum was obtained by centrifugation of venous blood collected prior to surgery at 1,000-2,000 x $\mathrm{g}$ for $10 \mathrm{~min}$, which was stored frozen at $-80^{\circ} \mathrm{C}$ and thawed at the time of measurement. HGF levels were measured using a two-step sandwich HGF ELISA kit (Otsuka, Tokyo, Japan), which included the antibodies and o-Phenylenediamine substrate solution, according to the manufacturer's instructions. In the first reaction, $50 \mu \mathrm{l}$ phosphate-buffered saline (PBS; Wako Pure Chemical Industries, Ltd, Osaka, Japan) and $50 \mu 1$ sample were added to each well of a microtiter plate, which was sealed and incubated at room temperature for $1 \mathrm{~h}$ with agitation. Following removal of the reaction mixture, the plate was washed five times with wash buffer (Wako Pure Chemical Industries, Ltd). Subsequently, $100 \mu \mathrm{l} /$ well rabbit polyclonal anti-HGF primary antibody was added for the second reaction and incubated for $1 \mathrm{~h}$ at room temperature. Following aspiration and washing five times, $100 \mu \mathrm{l} /$ well of the horseradish peroxidase-conjugated goat anti-rabbit immunoglobulin $\mathrm{G}$ secondary antibody was added for the third reaction and incubated for $1 \mathrm{~h}$ at room temperature. Following aspiration and washing five times, $100 \mu \mathrm{l} /$ well o-Phenylenediamine substrate solution was added. Following incubation at room temperature for $10 \mathrm{~min}$, the reaction was stopped by adding $100 \mu \mathrm{l}$ of stop solution. Absorbance was measured at $420 \mathrm{~nm}$ using a microplate reader (SpectraMax Plus 384; Molecular Devices, Sunnyvale, CA, USA), and HGF levels were determined using a standard curve.

Immunohistological analysis. HGF: Following deparaffinization with petroleum benzene (Kanto Chemical Co., Inc., Tokyo, Japan) of the $20 \%$ formalin-fixed (Wako Pure Chemical Industries, Ltd) paraffin-embedded (Junsei Chemical Co., Ltd, Tokyo, Japan) sections ( $4 \mu \mathrm{m})$, which included the innermost tumor portion of each gastric cancer primary focus, the sections were immersed in PBS and exposed to microwaves at $95^{\circ} \mathrm{C}$ for $15 \mathrm{~min}$ to activate the antigens. Subsequently, the tissue sections were treated with $3 \% \mathrm{H}_{2} \mathrm{O}_{2}$ (Sankyo Kagaku Yakuhin Co., Ltd, Kanagawa, Japan) for 20 min to remove the intrinsic peroxidase activity and immunohistochemical staining was performed using the avidin-biotin-peroxidase complex (ABC) method. Following dilution of the reaction with normal horse serum at room temperature for $10 \mathrm{~min}$, rabbit polyclonal anti-human HGF antibody (dilution, 1:20; IBL Co., Ltd, Gunma, Japan) was used as the primary antibody and incubation was continued at room temperature for $60 \mathrm{~min}$. This was followed by reaction with a biotin-conjugated anti-mouse immunoglobulin G secondary antibody (DAKO Japan, Kyoto, Japan) at room temperature for $30 \mathrm{~min}$ and reaction with the ABC reagent (DAKO, Glostrup, Denmark) at room temperature for $30 \mathrm{~min}$. The color was developed by addition of 20\% 3,3'-diaminobenzidine tetrahydrochloride (Dojindo Laboratories, Kumamoto, Japan), the nuclei were stained with hematoxylin (Merck Millipore KGaA, Darmstadt, Germany) and the sections were dehydrated.

c-Met: c-Met was assayed in a similar manner to HGF, except that the antigen was activated by autoclaving at $95^{\circ} \mathrm{C}$ for $15 \mathrm{~min}$ and a rabbit polyclonal anti-human c-Met primary antibody (dilution, 1:20; IBL Co., Ltd.) was allowed to react at room temperature for $1 \mathrm{~h}$.

Microscopic examination of $\mathrm{HGF}$ and c-Met was performed on the tip of the tumor, particularly the innermost section. Three fields of each section were observed at 200x magnification using a BHS/System Living microscope (Olympus Corp., Tokyo, Japan) and the results were classified as positive when the ratio of stained cancer cells was $>25 \%$, according to previous studies that were analyzed for comparison (Fig. 1) (8,29-31).

Statistical analysis. JMP version 9.0.2 statistical software (SAS Institute, Inc., Cary, NC, USA) was used for statistical analyses. Values are presented as the mean \pm SD. The Mann-Whitney $U$ test was used to compare differences between two independent groups. Cumulative survival rates were calculated using the 
Table I. Clinicopathological factors and serum HGF.

\begin{tabular}{|c|c|c|c|}
\hline Factor & $\mathrm{n}$ & Serum HGF (pg/ml) & P-value \\
\hline Gastric cancer & 110 & $391.02 \pm 68.44$ & $<0.0001$ \\
\hline Control & 200 & $193.30 \pm 52.00$ & \\
\hline \multicolumn{4}{|l|}{ Stage $^{a}$} \\
\hline IA & 55 & $381.21 \pm 65.92$ & NS \\
\hline IB & 18 & $414.41 \pm 82.48$ & \\
\hline II & 16 & $378.28 \pm 47.01$ & \\
\hline IIIA & 9 & $404.64 \pm 65.95$ & \\
\hline IIIB & 6 & $402.38 \pm 93.44$ & \\
\hline IV & 6 & $412.94 \pm 71.45$ & \\
\hline \multicolumn{4}{|l|}{ Depth } \\
\hline $\mathrm{m}$ & 28 & $378.89 \pm 58.81$ & NS \\
\hline $\mathrm{sm}$ & 31 & $384.87 \pm 69.89$ & \\
\hline $\mathrm{mp}$ & 11 & $386.97 \pm 98.72$ & \\
\hline SS & 18 & $403.36 \pm 54.88$ & \\
\hline $\mathrm{s}$ & 22 & $407.04 \pm 71.75$ & \\
\hline \multicolumn{4}{|l|}{$\mathrm{INF}^{\mathrm{a}}$} \\
\hline$\alpha$ & 22 & $369.65 \pm 68.93$ & $<0.001(\alpha . \beta$ vs. $\gamma)$ \\
\hline$\beta$ & 37 & $367.34 \pm 59.68$ & \\
\hline$\gamma$ & 44 & $418.42 \pm 67.72$ & \\
\hline \multicolumn{4}{|c|}{ Histological type } \\
\hline well & 25 & $387.23 \pm 54.56$ & NS \\
\hline $\bmod$ & 26 & $379.56 \pm 80.35$ & \\
\hline poor & 45 & $399.25 \pm 70.48$ & \\
\hline sig & 6 & $404.95 \pm 74.10$ & \\
\hline muc & 3 & $361.36 \pm 77.65$ & \\
\hline pap & 4 & $396.12 \pm 54.23$ & \\
\hline \multicolumn{4}{|c|}{ Macroscopic type } \\
\hline 0 & 59 & $382.03 \pm 64.39$ & NS \\
\hline 0 -advanced & 9 & $364.13 \pm 68.61$ & \\
\hline 1 & 4 & $426.32 \pm 66.53$ & \\
\hline 2 & 16 & $404.70 \pm 87.33$ & \\
\hline 3 & 10 & $402.00 \pm 43.63$ & \\
\hline 4 & 11 & $423.53 \pm 72.43$ & \\
\hline 5 & 1 & $335.54 \pm 0.000$ & \\
\hline \multicolumn{4}{|c|}{ Lymphatic invasion } \\
\hline ly0 & 48 & $384.71 \pm 63.69$ & NS \\
\hline ly 1 & 37 & $391.22 \pm 70.67$ & \\
\hline $\operatorname{ly} 2$ & 21 & $398.01 \pm 76.63$ & \\
\hline $\operatorname{ly} 3$ & 4 & $428.13 \pm 68.74$ & \\
\hline \multicolumn{4}{|c|}{ Venous invasion } \\
\hline v0 & 89 & $387.92 \pm 67.32$ & NS \\
\hline v1 & 20 & $404.99 \pm 75.03$ & \\
\hline $\mathrm{v} 2$ & 1 & $387.52 \pm 0.000$ & \\
\hline \multicolumn{4}{|c|}{ Lymph node metastasis } \\
\hline n0 & 78 & $391.17 \pm 70.37$ & NS \\
\hline n1 & 17 & $382.79 \pm 58.94$ & \\
\hline $\mathrm{n} 2$ & 13 & $394.60 \pm 68.08$ & \\
\hline n3 & 0 & & \\
\hline $\mathrm{n} 4$ & 2 & $431.73 \pm 116.00$ & NS \\
\hline
\end{tabular}


Table I. Continued.

\begin{tabular}{|c|c|c|c|}
\hline Factor & $\mathrm{n}$ & Serum HGF (pg/ml) & P-value \\
\hline \multicolumn{4}{|c|}{ Peritoneal dissemination } \\
\hline p0 & 105 & $389.37 \pm 68.19$ & NS \\
\hline $\mathrm{p} 1$ & 5 & $425.58 \pm 71.99$ & \\
\hline \multicolumn{4}{|c|}{ Tumor size, mm } \\
\hline$\leqq 70$ & 97 & $384.64 \pm 66.22$ & NS \\
\hline$>70$ & 10 & $428.09 \pm 61.82$ & \\
\hline
\end{tabular}

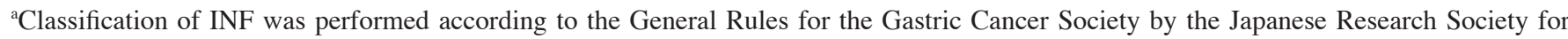
Gastric Cancer. Values are expressed as the mean \pm standard deviation. HGF, hepatocyte growth factor; NS, not significant; m, mucosa; sm, submucosa; mp, muscularis propria; ss, subserosa; s, serosa; INF, infiltrative growth pattern; INF $\alpha$, expansive type (tumor margin is clear); INF $\beta$, intermediate type; INF $\gamma$, invasive type (tumor margin is unclear); well, well-differentiated tubular adenocarcinoma; mod, moderately differentiated tubular adenocarcinoma; poor, poorly differentiated adenocarcinoma; sig, signet-ring cell carcinoma; muc, mucinous adenocarcinoma; pap, papillary adenocarcinoma.
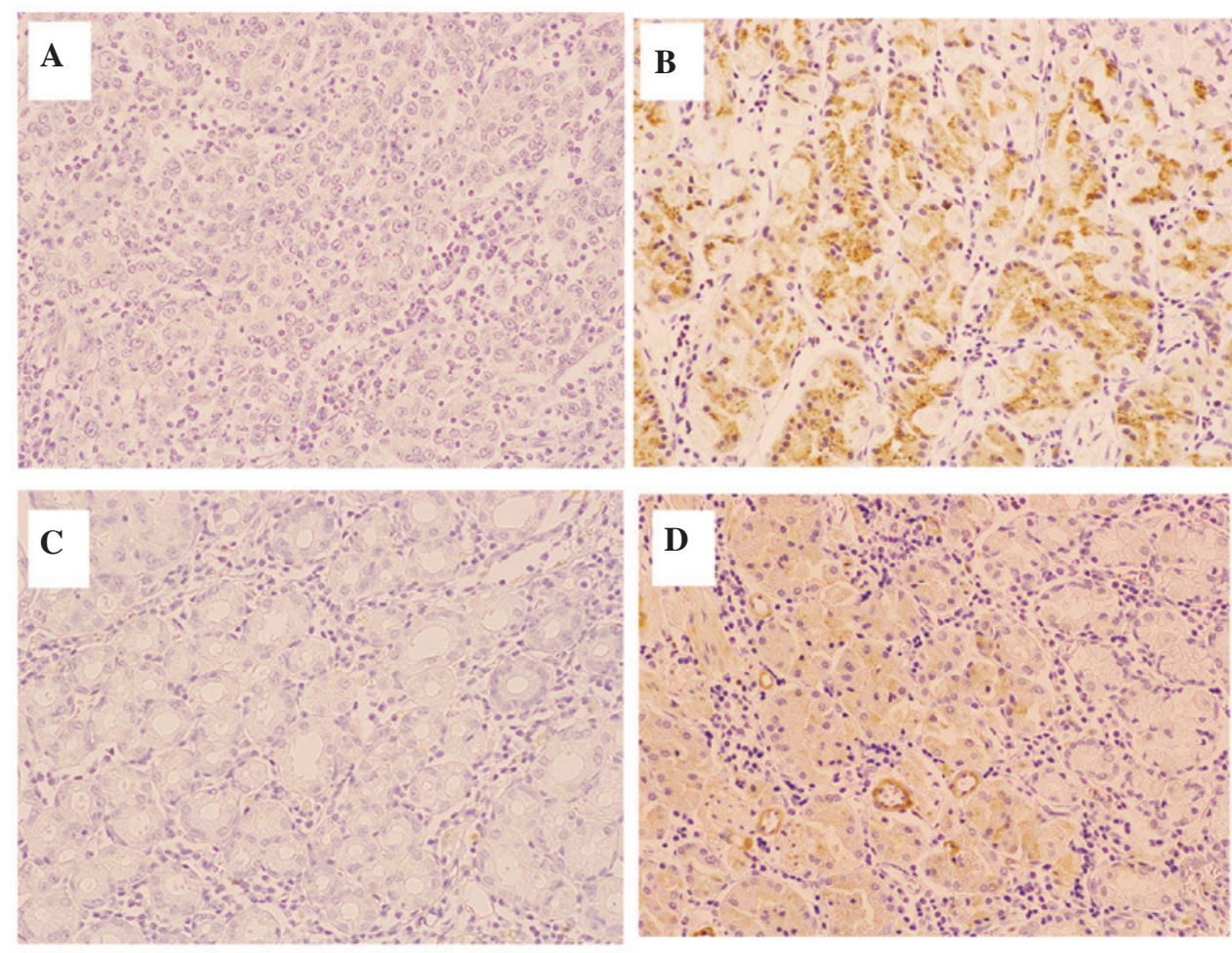

Figure 1. Immunostaining of HGF and c-Met. Microscopic examination was conducted on the tip of the tumor, particularly the innermost part. By observing three fields at 200x magnification, the results were classified as positive if the ratio of stained cancer cells was $>25 \%$, as analyzed by comparison. (A) Negative HGF staining. (B) Positive HGF staining. (C) Negative c-Met staining. (D) Positive c-Met staining. HGF, hepatocyte growth factor.

Kaplan-Meier method and distributions were identified using the log-rank test. $\mathrm{P}<0.05$ was considered to indicate a statistically significant difference between values.

The terminology used in this report is in accordance with the General Rules of the Gastric Cancer Society by the Japanese Research Society for Gastric Cancer (28).

\section{Results}

Serological analysis of HGF. Significant differences were detected in preoperative HGF levels between the gastric cancer and control groups (391.0 \pm 68.4 vs. $193.3 \pm 52.0 \mathrm{pg} / \mathrm{ml}$, respectively; $\mathrm{P}<0.0001)$. There was no correlation between preoperative serum HGF levels and patient age or gender. The results of analyses to identify correlations between serum HGF levels and clinicopathological factors are shown in Table I. Advanced progression in the INF $\alpha / \beta$ vs. INF $\gamma$ was correlated with elevated preoperative serum HGF levels $(\mathrm{P}<0.001)$. Although there was no significant difference in tumor diameter, invasion depth or lymphatic vessel invasion (ly), preoperative serum HGF levels increased as the disease progressed. In patients with peritoneal dissemination, serum HGF levels were frequently increased. 
Table II. Correlation between HGF/c-Met overexpression and clinicopathological factors.

\begin{tabular}{|c|c|c|c|c|c|c|c|c|}
\hline \multirow[b]{2}{*}{ Factor } & \multirow[b]{2}{*}{$\mathrm{n}$} & \multirow[b]{2}{*}{ subtotal } & \multicolumn{3}{|c|}{ HGF expression } & \multicolumn{3}{|c|}{ c-Met expression } \\
\hline & & & $(-)$ & $(+)$ & P-value & $(-)$ & $(+)$ & P-value \\
\hline All & 50 & & 14 & 36 & & 25 & 25 & \\
\hline \multicolumn{9}{|l|}{ Gender } \\
\hline Male & 38 & & & & & & & \\
\hline Female & 12 & & & & & & & \\
\hline \multicolumn{9}{|l|}{ Stage } \\
\hline IA & 25 & 41 & 12 & 29 & NS & 23 & 18 & NS \\
\hline IB & 7 & & & & & & & \\
\hline II & 9 & & & & & & & \\
\hline IIIA & 4 & 9 & 2 & 7 & & 2 & 7 & \\
\hline IIIB & 2 & & & & & & & \\
\hline IV & 3 & & & & & & & \\
\hline \multicolumn{9}{|l|}{ Depth } \\
\hline $\mathrm{m}$ & 13 & 13 & 5 & 8 & NS & 9 & 4 & NS \\
\hline $\mathrm{sm}$ & 15 & 37 & 9 & 28 & & 16 & 21 & \\
\hline $\mathrm{mp}$ & 5 & & & & & & & \\
\hline ss & 8 & & & & & & & \\
\hline se & 9 & & & & & & & \\
\hline \multicolumn{9}{|l|}{ INF } \\
\hline$\alpha$ & 10 & 32 & 10 & 22 & NS & 16 & 16 & NS \\
\hline$\beta$ & 22 & & & & & & & \\
\hline$\gamma$ & 17 & 17 & 3 & 14 & & 8 & 9 & \\
\hline \multicolumn{9}{|c|}{ Histological type } \\
\hline well & 12 & 23 & 5 & 18 & NS & 11 & 12 & NS \\
\hline $\bmod$ & 11 & & & & & & & \\
\hline poor & 20 & 25 & 8 & 17 & & 13 & 12 & \\
\hline sig & 5 & & & & & & & \\
\hline muc & 1 & & & & & & & \\
\hline pap & 1 & & & & & & & \\
\hline \multicolumn{9}{|c|}{ Lymphatic invasion } \\
\hline ly0 & 27 & 43 & 12 & 31 & NS & 24 & 19 & 0.0416 \\
\hline ly1 & 16 & & & & & & & \\
\hline ly 2 & 4 & 7 & 2 & 5 & & 1 & 6 & \\
\hline ly3 & 3 & & & & & & & \\
\hline \multicolumn{9}{|c|}{ Venous invasion } \\
\hline v0 & 43 & 43 & 11 & 32 & NS & 23 & 20 & NS \\
\hline v1 & 7 & 7 & 3 & 4 & & 2 & 5 & \\
\hline v2 & 0 & & & & & & & \\
\hline \multicolumn{9}{|c|}{ Lymph node metastasis } \\
\hline n0 & 34 & 45 & 12 & 33 & NS & 25 & 20 & 0.0184 \\
\hline $\mathrm{n} 1$ & 11 & & & & & & & \\
\hline $\mathrm{n} 2$ & 5 & 5 & 2 & 3 & & 0 & 5 & \\
\hline n3 & 0 & & & & & & & \\
\hline $\mathrm{n} 4$ & 0 & & & & & & & \\
\hline \multicolumn{9}{|c|}{ Peritoneal dissemination } \\
\hline $\mathrm{p} 0$ & 47 & 47 & 14 & 33 & NS & 24 & 23 & NS \\
\hline $\mathrm{p} 1$ & 3 & 3 & 0 & 3 & NS & 1 & 2 & NS \\
\hline
\end{tabular}


Table II. Continued.

\begin{tabular}{|c|c|c|c|c|c|c|c|c|}
\hline \multirow[b]{2}{*}{ Factor } & \multirow[b]{2}{*}{$\mathrm{n}$} & \multirow[b]{2}{*}{ subtotal } & \multicolumn{3}{|c|}{ HGF expression } & \multicolumn{3}{|c|}{ c-Met expression } \\
\hline & & & $(-)$ & $(+)$ & P-value & $(-)$ & $(+)$ & P-value \\
\hline \multicolumn{9}{|c|}{ Tumor size (mm) } \\
\hline$\leq 50$ & 38 & 38 & 12 & 26 & NS & 22 & 16 & 0.0469 \\
\hline$>50$ & 12 & 12 & 2 & 10 & & 3 & 9 & \\
\hline \multicolumn{9}{|c|}{ Serum HGF (pg/ml) } \\
\hline$\leq 400$ & 36 & 36 & 10 & 26 & NS & 17 & 19 & NS \\
\hline$>400$ & 14 & 14 & 4 & 10 & & 8 & 6 & \\
\hline
\end{tabular}

Mean age (standard deviation) of subjects, 61.8 (10.6) years. HGF, hepatocyte growth factor; SD, standard deviation; NS, not significant; m, mucosa; sm, submucosa; mp, muscularis propria; ss, subserosa; s, serosa; INF, infiltrative growth pattern; INF $\alpha$, expansive type (tumor margin is clear); INF $\beta$, intermediate type; INF $\gamma$, invasive type (tumor margin is unclear); well, well-differentiated tubular adenocarcinoma; mod, moderately differentiated tubular adenocarcinoma; poor, poorly differentiated adenocarcinoma; sig, signet-ring cell carcinoma; muc, mucinous adenocarcinoma; pap, papillary adenocarcinoma.

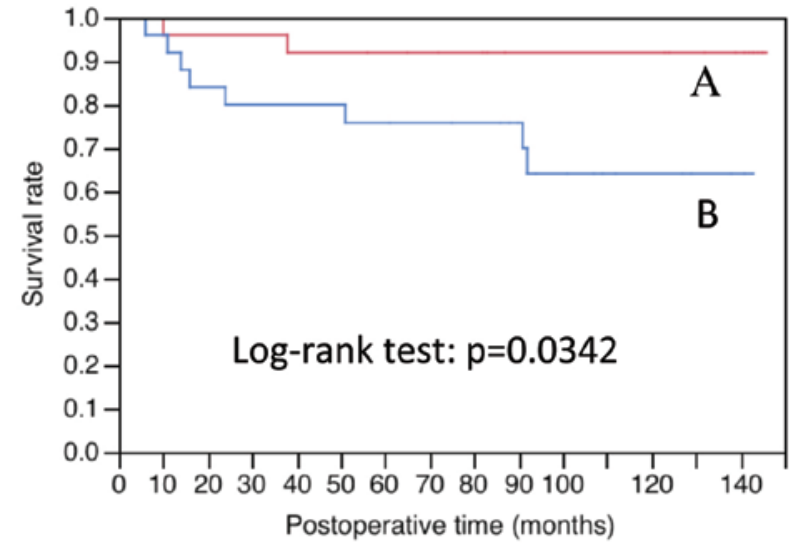

Figure 2. c-Met immunostaining and OS of subjects. OS of c-Met immunopositive cases $(\mathrm{n}=25)$ was significantly lower than that of $\mathrm{c}-\mathrm{Met}$ immunonegative cases $(n=25)$; log-rank test, $P=0.0342$. (A) Negative $c-M e t$ immunostaining. (B) Positive c-Met immunostaining. OS, overall survival.

Immunohistological analysis. Of the 50 cases analyzed, 36 (72\%) were HGF-positive and 14 (28\%) were HGF-negative, whereas $25(50 \%)$ were c-Met-positive and $25(50 \%)$ were c-Met-negative. No correlation was found between serum HGF levels in either staining. There was no correlation between the pathological factors analyzed and HGF levels, whereas a significant correlation was found between c-Met, which is a receptor of HGF, and lymphatic vessel invasion (ly0.1 vs. 2.3; $\mathrm{P}=0.0416)$, lymph node metastasis (n0.1 vs. $2 ; \mathrm{P}=0.0184$ ) and maximum tumor diameter $(\leq 50 \mathrm{~mm}$ vs. $>50 \mathrm{~mm} ; \mathrm{P}=0.0469)$ (Table II). The overall survival (OS) was significantly lower in c-Met-positive cases than that in c-Met-negative cases ( $\mathrm{P}=0.0342$; Fig. 2 and Table III).

\section{Discussion}

Cell growth factors, including HGF, constitute a significant group of molecules that regulate cell proliferation, migration and apoptosis in the dynamic organization of cell populations during embryogenesis, organogenesis and regeneration. Numerous factors amongst these additionally promote cell migration. It has been previously reported that HGF has the most potent effect on the promotion of cancer cell infiltration, the cell migration associated with the degradation of extracellular matrix components, including the basement membrane and collagen (9-16). Therefore, activation of the HGF/c-Met pathway results in the simultaneous activation of multiple signal transduction pathways that promote cancer cell infiltration. Antagonists of the HGF/c-Met pathway represent potential anti-cancer agents to inhibit cancer infiltration and metastasis, and therefore, the development of such antagonists is currently underway (27).

In the present study, serological and immunohistological analyses of the expression of the HGF/c-Met pathway in gastric cancer were performed in order to establish its clinical significance in the assessment of disease progression. To the best of our knowledge, no previous studies analyzing serum HGF levels and immunostaining for HGF and c-Met simultaneously with pathological factors were available in the literature.

Although elevated serum HGF levels in patients with gastric cancer had been previously reported (32-35), the present study aimed to determine whether this factor may be used in the assessment of disease progression. The results indicated that pre-operative serum HGF levels were significantly higher in patients with gastric cancer than those in the control group $(\mathrm{P}<0.0001)$, and that high HGF levels above the cut-off value $(297.3 \mathrm{pg} / \mathrm{ml}$; mean in the control+2 SD) were observed in $93.75 \%$ of patients, similar to that reported previously. However, the correlation between HGF levels and disease stage previously reported by Wu et al (32) and Han et al (33) was not observed in the present study, the results of which were similar to those reported by Taniguchi et al (34).

Conversely, advanced progression in the infiltrating growth pattern (INF $\alpha / \beta$ vs. INF $\gamma$ ) was significantly correlated with high preoperative serum HGF levels $(\mathrm{P}<0.001)$. Although this effect may be associated with the involvement of HGF in the infiltrating growth of cancer cells, this factor could not be 
Table III. Five-year survival rate and P-value for overall survival.

\begin{tabular}{|c|c|c|c|}
\hline Clinicopathological factor & $\mathrm{n}$ & Five-year survival rate & P-value \\
\hline \multicolumn{4}{|l|}{ Peritoneal dissemination } \\
\hline p0 & 47 & 0.893 & \multirow[t]{2}{*}{$<0.0001$ (p0 vs. 1$)$} \\
\hline $\mathrm{p} 1$ & 3 & 0.000 & \\
\hline \multicolumn{4}{|l|}{ Stage } \\
\hline $\mathrm{I} / \mathrm{II}$ & 41 & 0.975 & \multirow[t]{2}{*}{$<0.0001$ (I/II vs. III/IV) } \\
\hline III/IV & 9 & 0.222 & \\
\hline \multicolumn{4}{|l|}{ Tumor size (mm) } \\
\hline$<50$ & 38 & 0.920 & \multirow[t]{2}{*}{$0.0001(<50$ vs. $>50)$} \\
\hline$>50$ & 12 & 0.583 & \\
\hline \multicolumn{4}{|l|}{ Venous invasion } \\
\hline $\mathrm{v} 0$ & 43 & 0.906 & \multirow[t]{2}{*}{0.0011 (v0 vs. $1 / 2$ ) } \\
\hline $\mathrm{v} 1 / 2$ & 7 & 0.429 & \\
\hline \multicolumn{4}{|l|}{ Lymphatic invasion } \\
\hline ly0/1 & 43 & 0.906 & \multirow[t]{2}{*}{0.0017 (ly0/1 vs. $2 / 3)$} \\
\hline $\operatorname{ly} 2 / 3$ & 7 & 0.429 & \\
\hline \multicolumn{4}{|l|}{ Lymph node metastasis } \\
\hline $\mathrm{n} 0 / 1$ & 45 & 0.888 & \multirow[t]{2}{*}{0.0056 (n0/1 vs. 2) } \\
\hline $\mathrm{n} 2$ & 5 & 0.400 & \\
\hline \multicolumn{4}{|l|}{ Infiltrative growth pattern } \\
\hline $\mathrm{IFN} \alpha / \beta$ & 32 & 0.937 & \multirow[t]{2}{*}{$0.0083(\mathrm{IFN} \alpha / \beta$ vs. $\gamma)$} \\
\hline $\mathrm{IFN} \gamma$ & 17 & 0.647 & \\
\hline \multicolumn{4}{|l|}{ c-Met expression } \\
\hline$(-)$ & 25 & 0.920 & \multirow[t]{2}{*}{$0.0342[(-)$ vs. $(+)]$} \\
\hline$(+)$ & 25 & 0.758 & \\
\hline \multicolumn{4}{|l|}{ serum HGF (pg/ml) } \\
\hline$<400$ & 36 & 0.887 & \multirow[t]{2}{*}{$0.0558(<400$ vs. $>400)$} \\
\hline$>400$ & 14 & 0.714 & \\
\hline \multicolumn{4}{|l|}{ Histological type } \\
\hline well/mod & 23 & 0.920 & \multirow[t]{2}{*}{0.1793 (well/mod vs. por/sig) } \\
\hline poor/sig & 25 & 0.756 & \\
\hline \multicolumn{4}{|l|}{ Depth } \\
\hline $\mathrm{m}$ & 13 & 0.917 & \multirow[t]{2}{*}{$0.2649(\mathrm{~m}$ vs. sm/mp/ss/se) } \\
\hline $\mathrm{sm} / \mathrm{mp} / \mathrm{ss} / \mathrm{se}$ & 37 & 0.811 & \\
\hline \multicolumn{4}{|l|}{ HGF expression } \\
\hline$(-)$ & 14 & 0.929 & \multirow[t]{2}{*}{$0.5385[(-)$ vs. $(+)]$} \\
\hline$(+)$ & 36 & 0.806 & \\
\hline
\end{tabular}

HGF, hepatocyte growth factor; m, mucosa; sm, submucosa; mp, muscularis propria; ss, subserosa; s, serosa; INF, infiltrative growth pattern; INF $\alpha$, expansive type (tumor margin is clear); INF $\beta$, intermediate type; INF $\gamma$, invasive type (tumor margin is unclear); well, well-differentiated tubular adenocarcinoma; mod, moderately differentiated tubular adenocarcinoma; poor, poorly differentiated adenocarcinoma; sig, signet-ring cell carcinoma; muc, mucinous adenocarcinoma; pap, papillary adenocarcinoma.

evaluated because, to the best of our knowledge, no other study on infiltrating growth patterns was available in the literature.

HGF levels were not significantly correlated with certain parameters, including tumor diameter, invasion depth and ly factors; however, preoperative serum HGF levels were elevated as the disease progressed. Regarding the association between HGF levels and invasion depth (pT factor), Niki et al (35) identified a significant difference between pT1 and pT2-4 tumors.
Although a significant difference in HGF levels was not detected in patients with peritoneal dissemination, there was a tendency towards high HGF levels among these patients.

Subjects for the present study were selected randomly; therefore no patient with liver metastasis was included. Niki et al (35) reported a significant elevation in serum HGF levels in patients diagnosed with liver metastasis, whereas Taniguchi et al (34) reported that there was no significant difference in serum HGF 
levels in patients with relapse independent of liver metastasis. Therefore, the preoperative serum HGF levels in patients with gastric cancer represent a potential predictive factor for disease progression, as observed in colon cancer (6).

In the present study, no correlation was identified between serum HGF levels and immunostaining for HGF or c-Met in tissue preparations; this was potentially due to the complex paracrine and autocrine mechanisms of $\mathrm{HGF}$ in cancer cells $(36,37)$. Therefore, the significance of HGF expression in the microenvironment surrounding tumors requires further investigation.

Although there was no correlation between pathological factors and immunostaining for HGF, a significant correlation was identified between c-Met, which is a receptor of HGF, and lymphatic vessel invasion (ly0.1 vs. $2.3, \mathrm{P}=0.0416$ ), lymph node metastasis (n0.1 vs. $2, \mathrm{P}=0.0184$ ) and maximum tumor diameter $(<50 \mathrm{~mm}$ vs. $>50 \mathrm{~mm}, \mathrm{P}=0.0469)$. Correlations between immunostaining for $\mathrm{c}-\mathrm{Met}$ and various pathological factors, particularly invasion depth and disease stage, have been reported in previous studies (38-46). In the present study, cases were selected randomly for immunostaining analysis, as for serological analysis. It was demonstrated that $41(82 \%)$ of the 50 cases analyzed were stage I or II, and $28(56 \%)$ had an invasion depth of $\mathrm{m}$ or sm, indicating that the majority of the cohort comprised relatively early stage cancer cases. Only three $(6 \%)$ cases that were Peritoneum dissemination-factor-positive were stage IV. These results likely explain the absence of statistically significant differences between immunostaining and invasion depth or disease stage.

However, in the present study, which included numerous relatively early cancer cases, the OS of c-Met immunostaining-positive cases was significantly lower than that of negative cases $(\mathrm{P}=0.0342)$, indicating that $\mathrm{c}-\mathrm{Met}$ positivity may be a prognostic factor for gastric cancer.

In chemotherapy for unresectable recurrent gastric cancer, the efficacy of trastuzumab was demonstrated in HER2-positive cases, which subsequently led to the use of personalized drug treatments with molecularly targeted drugs (47). Rilotumumab, which is a fully human monoclonal antibody against HGF and a ligand of the c-Met receptor, suppresses c-Met downstream signaling (47). In pre-clinical models, rilotumumab was shown to inhibit tumor progression in a HGF/c-Met- dependent manner, and its tolerability was verified in early clinical trials $(48,49)$. If future phase II/III trials are implemented under clinical trial designs that allow sufficient verification of the potential of c-Met expression as a biomarker to aid the identification of cases in which rilotumumab is effective, a field of c-Met-positive gastric cancer may be established, similarly to that of HER2-positive gastric cancer. Therefore, further basic studies regarding c-Met expression are required, particularly to improve quality control in immunostaining.

In conclusion, the results of the present study revealed that elevated pre-operative serum HGF levels were indicative of invasive growth of tumor foci, categorized as IFN $\gamma$, and characterized by high-grade tumors with an unclear border between the tumor and the surrounding tissue. c-Met-positive immunostaining indicated a tumor with a large diameter, advanced lymphatic vessel invasion and a high degree of lymph node metastasis, and may therefore be a factor indicating poor prognosis. Based on the results described above, the expression of the $\mathrm{HGF} / \mathrm{c}-\mathrm{Met}$ pathway in gastric cancer is a potential predictive factor for disease progression, as previously established for colon cancer.

\section{Acknowledgements}

The authors would like to thank Miho Tabe (SRL Laboratory, Tokyo, Japan) for providing the instrumentation. The authors would also like to thank Minoru Sakurada and Mizuho Karita (Department of Pathology, Tokyo Women's Medical University, Tokyo, Japan) for their technical advice.

\section{References}

1. Yamada A, Saito N, Kameoka S and Kobayashi M: Clinical significance of epidermal growth factor (EGF) expression in gastric cancer. Hepatogastroenterology 54: 1049-1052, 2007.

2. Hirosawa T, Saito N, Kameoka S and Kobayashi M: Clinical significance of epidermal growth factor (EGF) expression for assessing the spreading of human colon cancer. Nippon Daicho Komonbyo Gakkai Zasshi 55: 402-412, 2002 (In Japanese).

3. Soyama K, Saito N and Kameoka S: Study on adhesion molecule betal integrin in colorectal cancer-quantification of blood levels and immunohistological staining. Nippon Daicho Komonbyo Gakkai Zasshi 52: 119-127, 1999 (In Japanese).

4. Saito N, Nishimura $H$ and Kameoka S: Clinical significance of fibronectin expression in colorectal cancer. Mol Med Rep 1: 77-81, 2008.

5. Tani H, Saito N, Kobayashi M and Kameoka S: Clinical significance of keratinocyte growth factor and K-sam gene expression in gastric cancer. Mol Med Rep 7: 1381-1386, 2013.

6. Suda A, Saito N, Seshimo A, Kameoka S and Kobayashi M: Examination of transforming growth factor betal expression in the serum and tumor tissue of gastric cancer. Int Surg 94: 182-188, 2009.

7. Daiko W, Saito N and Kameoka S: Clinical significance of TGF-betal expression in evaluation of the malignancy of colorectal cancer. Nippon Daicho Komonbyo Gakkai Zasshi 58: 377-382, 2005 (In Japanese).

8. Hashimoto T, Saito N, Kameoka S, Shibata N and Kobayashi M: Clinical significance of hepatocyte growth factor and its specific receptor c-Met expression in colorectal cancer progression. Acta Histochem Cytochem 37: 139-146, 2004.

9. Nakamura T, Nawa K and Ichihara A: Partial purification and characterization of hepatocyte growth factor from serum of hepatectomized rats. Biochem Biophys Res Commun 122: $1450-1459,1984$

10. Nakamura T, Teramoto $H$ and Ichihara A: Purification and characterization of a growth factor from rat platelets for mature parenchymal hepatocytes in primary cultures. Proc Natl Acad Sci USA 83: 6489-6493, 1986.

11. Nakamura T, Nawa K, Ichihara A, Kaise $N$ and Nishino $T$ : Purification and subunit structure of hepatocyte growth factor from rat platelets. FEBS Lett 224: 311-316, 1987.

12. Nakamura T, Nishizawa T, Hagiya M, et al: Molecular cloning and expression of human hepatocyte growth factor. Nature 342 : 440-443, 1989.

13. Higashio K, Shima N, Goto M, et al: Identity of a tumor cytotoxic factor from human fibroblasts and hepatocyte growth factor. Biochem Biophys Res Commun 170: 397-404, 1990.

14. Stoker M and Gherardi E: Regulation of cell movement: the motogenic cytokines. Biochim Biophys Acta 1072: 81-102, 1991.

15. Nakamura T: Structure and function of hepatocyte growth factor. Prog Growth Factor Res 3: 67-85, 1991.

16. Botraro DP, Rubin JS, Faletro DL, et al: Identification of the hepatocyte growth factor receptor as the c-met proto-oncogene product. Science 251: 802-804, 1991.

17. Naldini L, Weidner KM, Vigna E, et al: Scatter factor and hepatocyte growth factor are indistinguishable ligands for the MET receptor. EMBO J 10: 2867-2878, 1991.

18. Conrotto P, Valdembri D, Corso S, et al: Sema4D induces angiogenesis through Met recruitment by Plexin B1. Blood 105: 4321-4329, 2005. 
19. Yi S and Tsao MS: Activation of hepatocyte growth factor-met autocrine loop enhances tumorigenicity in a human lung adenocarcinoma cell line. Neoplasia 2: 226-234, 2000.

20. Schmidt L, Duh FM, Chen F, et al: Germline and somatic mutations in the tyrosine kinase domain of the MET proto-oncogene in papillary renal carcinomas. Nat Genet 16: 68-73, 1997.

21. Schmidt L, Junker K, Weirich G, et al: Two North American families with hereditary papillary renal carcinoma and identical novel mutations in the MET proto-oncogene. Cancer Res 58: 1719-1722, 1998.

22. Park WS, Dong SM, Kim SY, et al: Somatic mutations in the kinase domain of the Met/hepatocyte growth factor receptor gene in childhood hepatocellular carcinomas. Cancer Res 59: 307-310, 1999.

23. Lee JH, Han SU, Cho H, et al: A novel germ line juxtamembrane Met mutation in human gastric cancer. Oncogene 19: 4947-4953, 2000.

24. Ma PC, Kijima T, Maulik G, et al: c-MET mutational analysis in small cell lung cancer: novel juxtamembrane domain mutations regulating cytoskeletal functions. Cancer Res 63: 6272-6281, 2003.

25. Ma PC, Jagdeesh S, Jagadeeswaran R, et al: c-MET expression/activation, functions and mutations in non-small cell lung cancer. Proc Am Assoc Cancer Res 44: 1875, 2004.

26. Christensen JG, Burrows J and Salgia R: c-Met as a target for human cancer and characterization of inhibitors for therapeutic intervention. Cancer Lett 225: 1-26, 2005.

27. Nakamura T, Sakai K, Nakamura T and Matsumoto $K$ : Hepatocyte growth factor twenty years on: Much more than a growth factor. J Gastroenterol Hepatol 26: 188-202, 2011.

28. Japanese Gastric Cancer Association: Gastric cancer 1. In Japanese Classification of Gastric Carcinoma. 2nd English Edition. June 1998, pp10-24.

29. Hattori $\mathrm{Y}$, Itoh $\mathrm{H}$, Uchino $\mathrm{S}$, et al: Immunohistochemical detection of K-sam protein in stomach cancer. Clin Cancer Res 2: 1373-1381, 1996

30. Maeda K, Chung YS, Ogawa Y, et al: Prognostic value of vascular endothelial growth factor expression in gastric carcinoma. Cancer 77: 858-863, 1996.

31. Nishimoto N: Identification of clinicopathological and molecular prognostic factors in patients of gastric cancer by multivariate analyses. Hiroshima J Med Sci 49: 171-181, 2001 (In Japanese).

32. Wu CW, Chi CW, Su TL, Liu TY, Lui WY and P'eng FK: Serum hepatocyte growth factor level associate with gastric cancer progression. Anticancer Res 18: 3657-3659, 1998.

33. Han SU, Lee JH, Kim WH, Cho YK and Kim MW: Significant correlation between serum level of hepatocyte growth factor and progression of gastric carcinoma. World J Surg 23: 1176-1180, 1999.

34. Taniguchi T, Kitamura M, Arai K, Iwasaki Y, Yamamoto Y, Igari $\mathrm{A}$ and Toi M: Increase in the circulating level of hepatocyte growth factor in gastric cancer patients. Br J Cancer 75: 673-677, 1997.

35. Niki M, Okajima K, Isozaki H, et al: Clinical evaluation of preoperative measurement of the serum human hepatocyte growth factor levels in patients of gastric cancer. Jpn J Gastroenterol Surg 28: 2139-2144, 1995 (In Japanese)
36. Ide T, Kitajima Y, Miyoshi A, et al: Tumor-stromal cell interaction under hypoxia increases the invasiveness of pancreatic cancer cells through the hepatocyte growth factor/c-Met pathway. Int J Cancer 119: 2750-2759, 2006.

37. Jiang WG, Martin TA, Parr C, Davies G, Matsumoto K and Nakamura T: Hepatocyte growth factor, its receptor, and their potential value in cancer therapies. Crit Rev Oncol Hematol 53: 35-69, 2005.

38. Catenacci DV, Cervantes G, Yala S, et al: RON (MST1R) is a novel prognostic marker and therapeutic target for gastroesophageal adenocarcinoma. Cancer Biol Ther 12: 9-46, 2011.

39. Li Y, Chen CQ, He YL, Cai SR, Yang DJ, et al: Abnormal expression of e-cadherin in tumor cells is associated with poor prognosis of gastric carcinoma. J Surg Oncol 106: 304-310, 2012.

40. Taniguchi K, Yonemura Y, Nojima N, et al: The relation between the growth patterns of gastric carcinoma and the expression of hepatocyte growth factor receptor (c-met), autocrine motility factor receptor, and urokinase-type plasminogen activator receptor. Cancer 82: 2112-2122, 1998.

41. Nakajima M, Sawada H, Yamada Y, et al: The prognostic significance of amplification and overexpression of c-met and c-erb B-2 in human gastric carcinomas. Cancer 85: 1894-1902, 1999.

42. Huang TJ, Wang JY, Lin SR, Lian ST and Hsieh JS: Overexpression of the c-met protooncogene in human gastric carcinoma: Correlation to clinical features. Acta Oncol 40 638-643, 2001.

43. Kubicka S, Claas C, Staab S, et al: p53 mutation pattern and expression of c-erbB2 and c-met in gastric cancer: relation to histological subtypes, Helicobacter pylori infection, and prognosis. Dig Dis Sci 47: 114-121, 2002.

44. Han SU, Lee HY, Lee JH, et al: Modulation of E-cadherin by hepatocyte growth factor induces aggressiveness of gastric carcinoma. Ann Surg 242: 676-683, 2005.

45. Drebber U, Baldus SE, Nolden B, et al: The overexpression of c-met as a prognostic indicator for gastric carcinoma compared to p53 and p21 nuclear accumulation. Oncol Rep 19: 1477-1483, 2008.

46. Zhao J, Zhang X and Xin Y: Up-regulated expression of Ezrin and c-Met proteins are related to the metastasis and prognosis of gastric carcinomas. Histol Histopathol 26: 1111-1120, 2011.

47. Iveson T, Donehower RC, Davidenko I, et al: Rilotumumab in combination with epirubicin, cisplatin, and capecitabine as first-line treatment for gastric or oesophagogastric junction adenocarcinoma: an open-label, dose de-escalation phase 1b study and a double-blind, randomised phase 2 study. Lancet Oncol 15: 1007-1018, 2014.

48. Davidenko I, Iveson T, Donehower RC, et al: Updated efficacy, biomarker, and exposure-response data form a phase 2 study of rilotumumab $(\mathrm{R})$ plus epirubicin, cisplatin, and capecitabine $(\mathrm{ECX})$ in gastric $(\mathrm{G})$ or esophagogastric junction (EGJ) cancer. In: European Society for Medical Oncology Congress. Vienna, 687P, 2012.

49. Yasuhide Yamada: Molecular therapy for gastric cancer. Chin Clin Oncol 2: 5, 2013 